OPEN ACCESS

Edited by:

Francesco Sofi,

University of Florence, Italy

Reviewed by:

Daniela Martini,

University of Milan, Italy

Thea Magrone,

University of Bari Aldo Moro, Italy

*Correspondence:

Andrew D. Fruge

fruge@auburn.edu

Specialty section: This article was submitted to

Nutritional Epidemiology,

a section of the journal

Frontiers in Nutrition

Received: 01 June 2020 Accepted: 28 August 2020 Published: 07 October 2020

Citation:

Schaberg MN, Smith KS, Greene MW and Frugé $A D$ (2020) Characterizing

Demographic and Geographical

Differences in Health Beliefs and Dietary Habits Related to Colon

Cancer Risk in US Adults.

Front. Nutr. 7:568643.

doi: 10.3389/fnut.2020.568643

\section{Characterizing Demographic and Geographical Differences in Health Beliefs and Dietary Habits Related to Colon Cancer Risk in US Adults}

\author{
Megan N. Schaberg, Kristen S. Smith, Michael W. Greene and Andrew D. Frugé* \\ Department of Nutrition, Dietetics, and Hospitality Management, Auburn University, Auburn, AL, United States
}

Background: Colon cancer (CC) risk is increased by behavioral factors including a diet high in red meat (RM) and processed meat; excess adiposity has contributed to a rise in $\mathrm{CC}$ in younger adults. The willingness of at-risk adults to modify behaviors to reduce CC risk warrants further investigation.

Methods: The previously validated Dietary Habits and Colon Cancer Beliefs Survey (DHCCBS) was used to assess attitudes and beliefs related to CC risk and diet behavior. An abbreviated food frequency questionnaire was included in the survey to quantify RM and green leafy vegetable (GLV) intake over the previous 30 days. Independent samples t-tests compared RM and GLV intake and DHCCBS responses. One-way analysis of variance with post-hoc LSD correction was completed to assess these differences within three age groups ( $<35,35-44$, and $45-54$ years old) and between U.S. Census Bureau geographical regions.

Results: Eight hundred and thirty eight survey responses were analyzed. Perceived severity of CC diagnosis was significantly lower in younger adults $(<35)$ compared to older adults (35-44, $p=0.042 ; 45-54, p=0.003)$. Furthermore, younger adults $(<35)$ perceived fewer barriers (i.e., taste preference) to GLV consumption than their older adult counterparts (35-44, $p=0.019 ; 45-54, p=0.002$ ). Few regional differences in habitual RM consumption were observed, however, several disparities were observed with GLV.

Conclusion: These findings from the DHCCBS indicate health beliefs toward CC risk are influenced by an individual's age and dietary habits. Additionally, regional differences in GLV consumption indicate opportunities for risk-reduction-focused health messages, particularly in the southern United States where CC incidence and mortality are highest.

Keywords: colon cancer, diet, health belief model, red meat, green leafy vegetables, health behavior

\section{INTRODUCTION}

Colon cancer (CC) is the third most common cancer in men and women in the United States (US), and the third leading cause of cancer deaths (1). Both hereditary and environmental factors contribute to CC risk, such that excess adiposity in adolescence confers $28 \%$ greater lifetime risk for CC in women (2). Increased waist circumference in adulthood alone is associated with a 53\% increased risk of CC (3). Though obesity is a multifactorial disease, diet is a major contributor to 
CC risk. In the US, $\sim 38.3 \%$ of new CC cases in 2015 were directly attributed to suboptimal diet (4). The Western diet, rich in red meat (RM) and processed foods and lacking in vegetables, is heavily implicated in CC development (5), with a recent meta-analysis indicating a $30 \%$ increased risk of CC for adults consuming this dietary pattern (6).

Heme, the iron-carrying molecule conferring color to RM, readily oxidizes lipids, and other molecules in the lumen of the colon, causing cytotoxicity and epithelial proliferation in the gut, which can promote carcinogenesis (7). Heme is composed of a porphyrin ring surrounding iron which is easily oxidized and absorbed primarily in the large intestine (8). When red or processed meats are consumed in excess, heme accumulates within the colon, contributing to cytotoxic effects (9). Furthermore, bacteria residing in the lumen interact with heme, producing toxic metabolites to further increase damage (10). Additionally, different cooking methods create varying amounts of mutagenic heterocyclic amines (11), although the effects of cooking methods on RM related CC risk is still being investigated in humans.

In contrast, diets with high green leafy vegetable (GLV) intake are associated with a decreased risk of CC (12). GLV are high in chlorophyll, fiber, and flavonoids and carotenoids, all of which are known for their anti-cancer effects. Chlorophyll, a structural analog to the porphyrin ring of heme, prevents mucosal damage, and hyperproliferation effects by competing with and binding to heme molecules (13). Fiber increases bowel motility and bacterial fermentation, decreasing the concentration of intestinal carcinogens (14). Flavonoids and carotenoids, which are abundant in GLVs, are associated with lowered risk of CC (15) and can reduce oxidative stress, increase apoptosis, and inhibit cell proliferation $(16,17)$.

Recommendations from the American Institute of Cancer Research (AICR) to reduce CC risk include behavioral changes in modifiable risk factors. These include consuming 5 servings of vegetables daily, with emphasis on 1 serving derived from GLV (18). The AICR also recommends reducing RM intake to $70 \mathrm{~g}$ per day or less. It has been observed that increased GLV consumption may be protective against CC in RM-rich diets (19), but disparities in dietary patterns, and health-seeking behaviors may confound epidemiological diet-related observations $(20,21)$. Finally, the American Cancer Society suggests CC screenings starting at the age of 45 with no known family history of CC (22). CC screenings are associated with a reduction in CC mortality; however, approximately half of the US population aged 50 and older do not comply with recommended CC screenings (23).

Awareness of risk factors associated with CC is important for reducing behaviors that could lead to CC development. However, knowledge of risk factors may not be sufficient to stimulate behavioral change (24). Western countries have been associated with an unwillingness of adults to adjust dietary patterns, regardless of the health outcome (25). Nonetheless, understanding the benefits of engaging in a health behavior can influence whether an individual will seek changes.

The Health Belief Model (HBM) utilizes five domains: perceived susceptibility, perceived severity, perceived benefit, perceived barriers, and cues to action, to examine healthrelated behaviors (24). This behavioral model has been used for almost seven decades; in recent years is has been used to understand behaviors ranging from the adherence of treatment for Tuberculosis, to the self-care attitudes of diabetics, and behaviors associated with cervical cancer risk (26-28). The Dietary Habits and Colon Cancer Beliefs Survey (DHCCBS) was developed and validated using the HBM to assess beliefs and attitudes related to diet and CC risk (29). Herein, we further analyzed associations between DHCCBS responses and dietary intake, within different age groups and US regions to explore the relationship between dietary habits and expected health outcomes in relation to CC risk.

\section{METHODS}

Auburn University's Institutional Review Board (IRB) granted approval for this study. Prior to starting the survey, participants were notified about confidentiality and their right to discontinue at any time. After reading the IRB information, consent was inferred via initiation of the survey. Participants were enlisted in May 2018 through the online portal Amazon Mechanical Turk (mTurk) to access the survey instrument. Compensation was given upon survey completion and validation of responses.

Methods of development and validation of the DHCCBS are published and can be readily accessed for further details (29). Briefly, 13 HBM Likert scale questions assessed the five domains of health behavior related to CC: one susceptibility question, two severity questions, two barrier questions, three benefits questions, and four cues-to-action questions. Twenty questions from the previously validated Dietary Health Questionnaire II (DHQII) quantified consumption of GLV and total RM (including beef, pork, lamb, and processed meats) over the previous 30 days (30). Three additional questions were added from the previously validated Meat Module Questionnaire (MMQ) to assess exposure to carcinogens in burgers, bacon, and steaks (31). Two attention check questions were included to validate survey responses and 8 questions assessed demographic and anthropometric information (age, sex, race, education, height and weight, and region). A goal sample size of 1,000 was determined using the rule of thumb: 10:1 subject to variable ratio (32). Serving sizes were estimated using frequency of intake over the last 30 days, as determined from DHQII responses, and multiplied by respective daily frequencies of consumption. Average weekly consumption amounts were converted into cooked-cup equivalents for GLV and ounce equivalents for RM and used to calculate total servings per day. One half cup of GLV and 2.5 ounces of RM were used as standards for servings of each respective food group. Methods for scoring the instrument were previously reported (29). Regional information was collected via zip code of respondents and characterized within the 4 regions of the US, according to the Census Bureau (33).

Exploratory analyses were conducted to evaluate relationships between DHCCBS questions and RM and GLV intake between age groups and regions. RM and GLV intake and DHCCBS responses were compared using independent sample $t$-tests. 
TABLE 1 | Characteristics of dietary habits and colon cancer beliefs survey respondents.

\begin{tabular}{|c|c|c|c|c|c|}
\hline & $\begin{array}{c}\text { Total } \\
(n=838)\end{array}$ & $\begin{array}{c}<35 \\
(n=487)\end{array}$ & $\begin{array}{c}35-44 \\
(n=227)\end{array}$ & $\begin{array}{c}45-54 \\
(n=124)\end{array}$ & $\begin{array}{c}\text { Between } \\
\text { group } \\
p \text {-value }\end{array}$ \\
\hline $\begin{array}{l}\text { GLV svgs/day Mean } \\
\text { (SD)* }\end{array}$ & $1.00(1.15)$ & $1.04(1.18)$ & $0.99(1.09)$ & $0.90(1.16)$ & 0.525 \\
\hline $\begin{array}{l}\text { RM svgs/day Mean } \\
\text { (SD)* }\end{array}$ & $0.93(0.94)$ & $0.96(0.98)$ & $0.93(0.97)$ & $0.81(0.66)$ & 0.494 \\
\hline Sex N (\%) & & & & & 0.001 \\
\hline Female & $429(51.2)$ & $223(45.8)$ & $132(58.1)$ & $74(59.7)$ & \\
\hline Male & 409 (48.8) & 264 (54.2) & 95 (41.9) & $50(40.3)$ & \\
\hline Race N (\%) & & & & & 0.008 \\
\hline Asian & $84(10)$ & $63(12.9)$ & $19(8.4)$ & $2(1.6)$ & \\
\hline Native American & $10(1.2)$ & $7(1.4)$ & $1(0.4)$ & $2(1.6)$ & \\
\hline Black & $49(5.8)$ & $33(6.8)$ & $11(4.8)$ & $5(4)$ & \\
\hline Pacific Islander & $2(0.2)$ & $1(0.2)$ & $1(0.4)$ & NA & \\
\hline White & $651(77.7)$ & 359 (73.7) & 180 (79.3) & 112 (90.3) & \\
\hline More than one race & $42(5)$ & $24(4.9)$ & $15(6.6)$ & $3(2.4)$ & \\
\hline Education $N(\%)$ & & & & & 0.296 \\
\hline$<$ High School & $4(0.5)$ & $3(0.6)$ & NA & $1(0.8)$ & \\
\hline HS Grad/GED & $81(9.7)$ & $51(10.5)$ & $17(7.5)$ & $13(10.5)$ & \\
\hline Some College & 209 (24.9) & 128 (26.3) & 49 (21.6) & $32(25.8)$ & \\
\hline Associate's Degree & $85(10.1)$ & $42(8.6)$ & $30(13.2)$ & $13(10.5)$ & \\
\hline Bachelor's Degree & $343(40.9)$ & 198 (40.7) & 102 (44.9) & $43(34.7)$ & \\
\hline Master's Degree & $92(11)$ & $48(9.9)$ & $25(11)$ & 19 (15.3) & \\
\hline Professional Degree & $17(2)$ & $13(2.7)$ & $3(1.3)$ & $1(0.8)$ & \\
\hline Doctorate & $7(0.8)$ & $4(0.8)$ & $1(0.4)$ & $2(1.6)$ & \\
\hline BMI category $N(\%)$ & & & & & 0.116 \\
\hline Underweight & $25(3)$ & $17(3.5)$ & $5(2.2)$ & $3(2.4)$ & \\
\hline Normal weight & $389(46.4)$ & 238 (48.9) & $103(45.4)$ & $48(38.7)$ & \\
\hline Overweight & 259 (30.9) & $151(31)$ & $64(28.2)$ & $44(35.5)$ & \\
\hline Obese & $165(19.7)$ & 81 (16.6) & $55(24.2)$ & $29(23.4)$ & \\
\hline Region N (\%) & & & & & 0.523 \\
\hline Northeast & $148(17.7)$ & 95 (19.5) & $32(14.1)$ & $21(16.9)$ & \\
\hline Midwest & $163(19.5)$ & 94 (19.3) & $43(18.9)$ & $26(21)$ & \\
\hline South & $284(33.9)$ & 157 (32.2) & $82(36.1)$ & 45 (36.3) & \\
\hline West & 212 (25.3) & 123 (25.3) & $63(27.8)$ & $26(21)$ & \\
\hline
\end{tabular}

${ }^{*}$ Amounts presented as servings per day, (1 serving $=2.5$ ounces $R M$ and 0.5 cooked cup equivalents GLV).

One-way analysis of variance (ANOVA) for each age group was used to compare individual barrier questions and RM and GLV consumption. Post-hoc analyses between barrier question responses were evaluated with LSD correction for multiple comparisons. Scores from the four questions within the cues to action domain were totaled together to generate one variable representing total domain score. Multivariable linear regression models were used to evaluate effectiveness of demographic predictors (i.e., sex, race, education, BMI category, and geographical region) on total scores from cues to action domain. Simple linear regression models were used to evaluate associated between DHCCBS questions on reported habitual GLV and RM servings per day within this subset of participants ( $n=838$ ). Responses were grouped into either disagree (including strongly disagree, disagree, and neither agree nor disagree responses) or agree (including strongly agree and agree responses), with disagree as the reference group for the models. Results were considered significant with a $p \leq 0.05$.

\section{RESULTS}

A total of 838 respondents were aged 54 years or less and included in the analysis. Respondents included $48.8 \%$ males, $77.7 \%$ white, and $54.4 \%$ had at least a bachelor's degree (Table 1). Males were overrepresented in the youngest age group and white adults were overrepresented in the oldest age group.

Relationships within age groups and DHCCBS responses were further explored in Table 2. Perceived quality of life-related severity of CC was significantly lower in younger adults $(<35)$ compared to older adult cohorts $(35-44, p=0.042 ; 45-54, p=$ $0.003)$. Additionally, older participants (45-54) reported greater perceived benefits of increasing GLV consumption to reduce CC risk than the younger age group $(<35 ; p=0.006)$. Interestingly, younger participants $(<35)$ received more recommendations from friends and family members to increase GLV intake in order to reduce CC risk $(35-44, p=0.033 ; 45-55, p=0.002)$.

GLV and RM intake were compared between US regions within these age groups to further understand these relationships. The middle age group (35-44) in the Southern US consumed significantly more RM than corresponding individuals in the Northeastern region $(p=0.021)$. Furthermore, each age group differed in GLV consumption between the South and West regions $(<35, p=0.050 ; 35-44, p=0.005 ; 45-54, p=$ 0.044; total, $p<0.001)$. Figures 1, 2 compare the different age groups and consumption of GLV and RM, respectively, within each region.

Several characteristics significantly predicted cues to action scores (Table 3). Predicted total scores of Asian (3.3 \pm 0.5 ) and Native American $(3.0 \pm 1.2)$ respondents were over three points higher than white respondents $(p<0.001 ; p=0.015$, respectively); and females were approximately one point lower than males $(p<0.001)$. Additionally, overweight and obese respondents had higher predicted scores than normal weight respondents ( $p=0.035 ; p=0.001$, respectively). Education and geographical location were not significant predictors of total cues to action scores.

Individuals who perceived high CC susceptibility were predicted to consume more GLV $(0.4 \pm 0.1)$ and less RM $(-0.3 \pm$ 0.1 ) compared to those with lower perceived CC susceptibility ( $p$ $<0.001)$. Additionally, those who perceived benefits of GLV were indeed predicted to consume more GLV $(-2.5 \pm 1.1)$ compared to those who did not perceive benefits from GLV consumption $(p=0.01)$. Furthermore, predicted RM consumption was higher in individuals who perceived barriers to eliminating RM intake $(-0.6 \pm 1.2 ; p<0.001)$. Supplementary Table 1 reports associations between reported habitual GLV and RM intake with DHCCBS questions. 
TABLE 2 | Dietary habits and colon cancer beliefs survey responses of US men and women.

\begin{tabular}{|c|c|c|c|c|c|}
\hline & Total & $<35$ & $35-44$ & $45-54$ & \\
\hline & Mean (SD) & Mean (SD) & Mean (SD) & Mean (SD) & Between group $p$-value \\
\hline \multicolumn{6}{|l|}{ Susceptibility } \\
\hline Please rate your perceived risk for developing colon cancer in your lifetime & $2.12(0.60)$ & $2.08(0.63)$ & $2.18(0.56)^{\star}$ & $2.17(0.58)$ & 0.068 \\
\hline \multicolumn{6}{|l|}{ Severity } \\
\hline Colon cancer can severely decrease my quality of life & $4.67(0.77)^{\S}$ & $4.61(0.85)^{\dagger \#}$ & $4.74(0.67)^{\star}$ & $4.77(0.59)^{\star}$ & 0.046 \\
\hline Colon cancer could lead to death & $4.7(0.70)^{\S}$ & $4.65(0.79)^{\dagger}$ & $4.78(0.57)^{\star}$ & $4.78(0.50)$ & 0.028 \\
\hline \multicolumn{6}{|l|}{ Perceived benefits } \\
\hline If I eat less red meat I could decrease my risk of developing colon cancer & $3.76(0.97)$ & $3.69(0.952)$ & $3.84(0.96)$ & $3.88(1.03)$ & 0.053 \\
\hline $\begin{array}{l}\text { If I eat more green leafy vegetables I could decrease my risk of developing } \\
\text { colon cancer }\end{array}$ & $4.14(0.85)^{\S}$ & $4.09(0.85)^{\#}$ & $4.15(0.85)$ & $4.32(0.81)^{\star}$ & 0.024 \\
\hline \multicolumn{6}{|l|}{ Perceived barriers } \\
\hline I don't like the taste of other protein-rich foods & $2.08(1.00)$ & $2.09(0.98)$ & $2.06(1.08)$ & $2.07(0.94)$ & 0.916 \\
\hline I don't like the taste of green leafy vegetables & $1.95(1.16)^{\S}$ & $2.06(1.19)^{\dagger+\#}$ & $1.85(1.16)^{\star}$ & $1.71(0.94)^{\star}$ & 0.003 \\
\hline I can't imagine never eating red meat & $3.25(1.53)$ & $3.26(1.53)$ & $3.3(1.55)$ & $3.14(1.48)$ & 0.628 \\
\hline \multicolumn{6}{|l|}{ Cues to action } \\
\hline A healthcare provider has recommended that I eat less red meat & $1.64(0.99)$ & $1.63(0.96)$ & $1.62(1.01)$ & $1.72(1.09)$ & 0.627 \\
\hline A friend or family member has recommended that I eat less red meat & $1.84(1.18)$ & $1.92(1.22)^{\dagger}$ & $1.72(1.14)^{\star}$ & $1.77(1.10)$ & 0.085 \\
\hline $\begin{array}{l}\text { A healthcare provider has recommended that I eat more green leafy } \\
\text { vegetables }\end{array}$ & $2.69(1.46)$ & $2.71(1.44)$ & $2.68(1.49)$ & $2.61(1.52)$ & 0.798 \\
\hline $\begin{array}{l}\text { A friend or family member has recommended that I eat more green leafy } \\
\text { vegetables }\end{array}$ & $2.78(1.49)^{\S}$ & $2.91(1.46)^{\dagger \#}$ & $2.66(1.52)^{\star}$ & $2.44(1.46)^{\star}$ & 0.003 \\
\hline
\end{tabular}

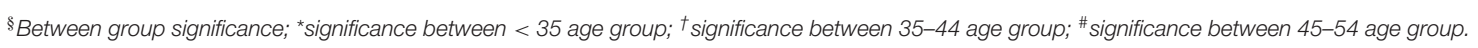

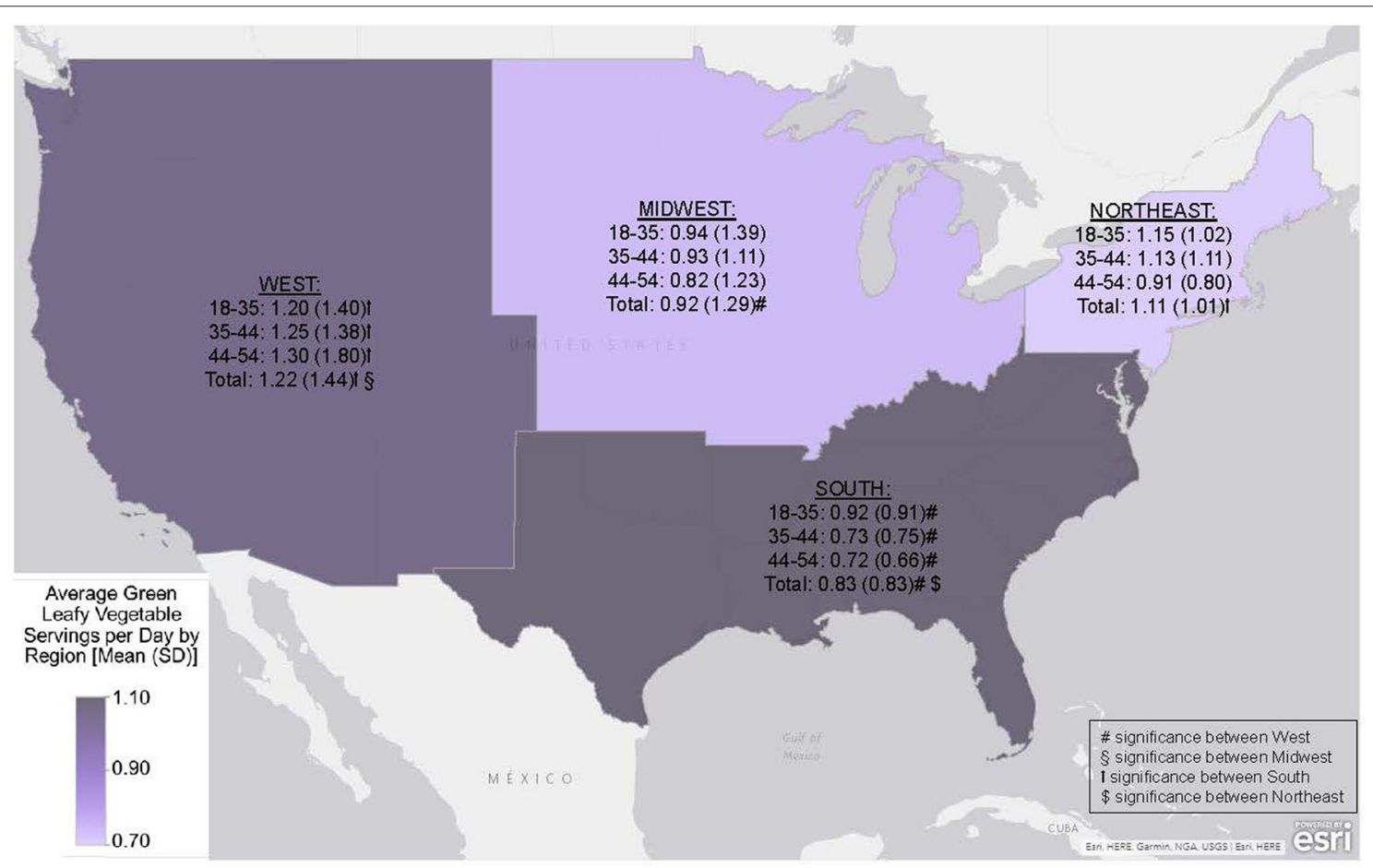

FIGURE 1 | Average green leafy vegetables (GLV) consumption within US Census Regions by age group ( 1 serving $=0.5$ cooked cup equivalent of GLV) Data is presented as mean (SD) and differences considered significant at $p<0.050$. 


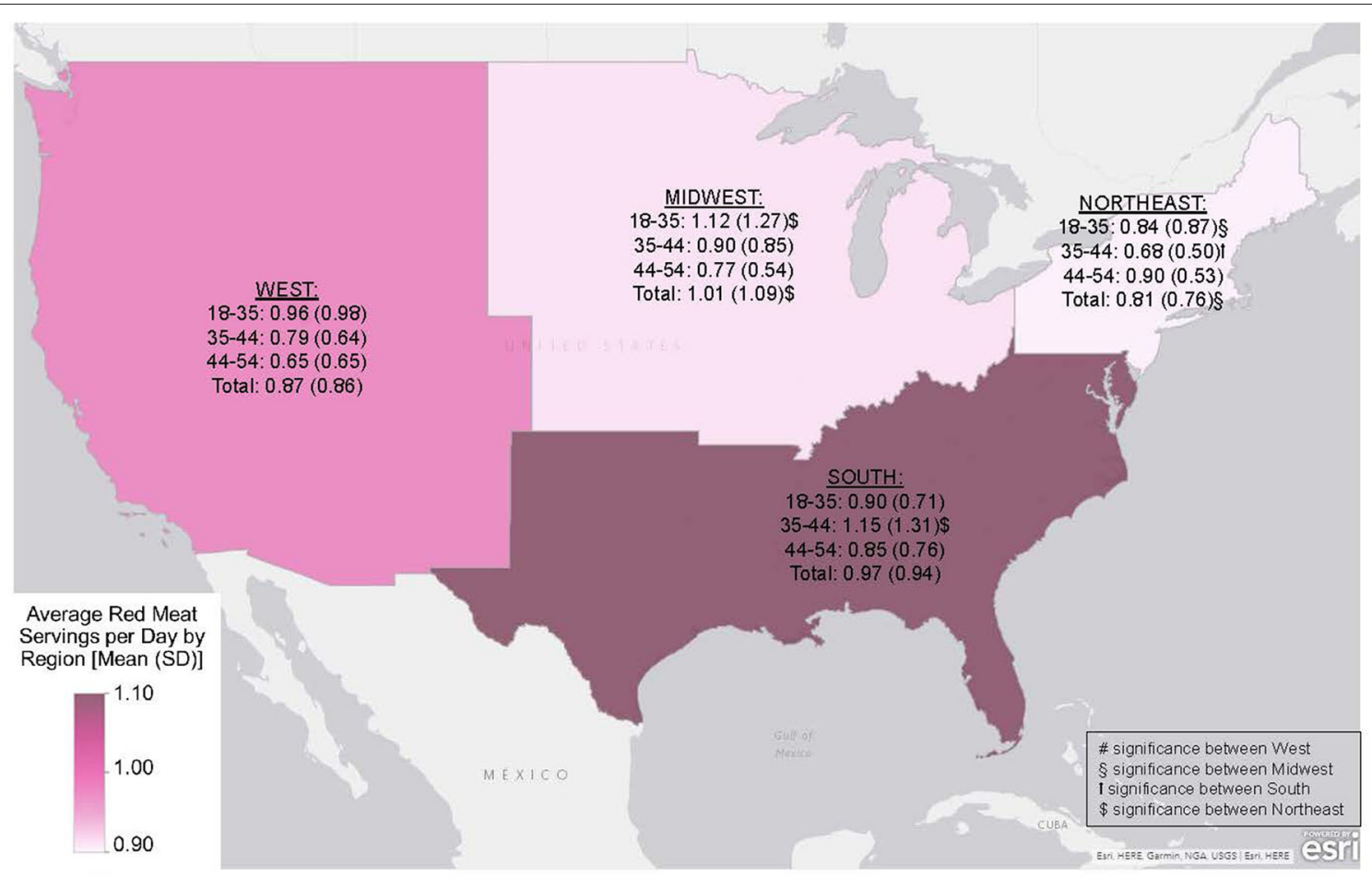

FIGURE 2 | Average red meat (RM) serving per day within US Census Regions by age group, presented as mean (SD) ( 1 serving $=2.5$ ounces RM). Differences considered significant at $p<0.05$.

\section{DISCUSSION}

These results suggest there are age-related disparities in health beliefs related to diet and CC, as well as regional differences in GLV and RM consumption. Specifically, GLV intake varied greatly between the southern and western US across all age groups. Survey respondents reported consuming almost twice the amount of RM compared to previous reports of 2015-2016 NHANES data (34). This is likely because we used FFQ to assess habitual intake as opposed to 24-h dietary recalls in NHANES and we included red processed meats in this value. Referencing NHANES 2015-2016 nutrient intake tables, mean daily Vitamin $\mathrm{K}$ consumption of $120.9 \mu \mathrm{g}$ would reflect $\sim 1 / 8$ cup GLV, which is similar to our observed 1 cup GLV per week (35).

Diet, as well as other biological and environmental factors, contribute to CC risk (36). Lagerlund et al. (37) estimate that approximately one third of cancers in the developing world could be prevented by addressing known modifiable risk factors. One study suggests providing health-related knowledge about the effects of meat intake is not sufficient to reduce meat consumption due to individuals' mistrust of information sources (38). This recent systematic review concluded that individuals do not consider reducing intake of specific foods to improve health; rather, they contemplate increasing intake of fruits and vegetables (38). Similarly, while individuals may be aware of this relationship between dietary habits and cancer risk, many lack the knowledge of which specific foods or nutrients influence this risk (39). A study by Sullivan et al. (40) concluded that individuals were more likely to change health-related behaviors when they believed their actions could influence a health-related outcome, regardless of their perceived risk for that outcome. Additionally, when surveyed about cancer prevention strategies, a majority of respondents did not consider nutrition as a prevention strategy (40). Moreover, an intervention providing personalized healthcare screenings tailored to individuals' gender and bodyweight status risks resulted in positive changes of unhealthy behaviors, with individuals increasing daily intake of fruits and vegetables (41). Aligning with current research, healthcare recommendations could have better success in behavioral change if the focus shifted from decreasing RM to increasing GLV intake. Healthcare interventions and recommendations focused on enhancing patients' knowledge of nutrition and corresponding risk could improve strategies for diminishing CC risk and increase adherence to these health-related behaviors.

Recent trends in CC epidemiology indicate a shift in what was once considered a rare cancer that only happened in older adults, and is now occurring increasingly in young adults (1). For both genders over the age of fifty, the incidence of CC has decreased (42). However, in a retrospective cohort study, the predicted incidence of CC by the year 2030 will increase by $90.0 \%$ for adults ages 20-34 (43). Our results indicate the younger participants do not recognize the severity of CC diagnosis compared to older participants; thus, younger adults at increased risk of CC due to lifestyle factors may benefit most from tailored public health messages. 
TABLE 3 | Multivariable linear regression analysis evaluating predicted Cues to Action scores between demographic groups of US adults completing the dietary habits and colon cancer beliefs survey.

\begin{tabular}{|c|c|c|c|c|c|}
\hline Variable & & $\begin{array}{l}\text { Predicted } \\
\text { total } \\
\text { scores }^{\#}\end{array}$ & B & SE & $p$-value* \\
\hline \multirow[t]{2}{*}{ Sex } & Male & 9.5 & Ref & & \\
\hline & Female & 8.5 & -0.988 & 0.276 & $<0.001$ \\
\hline \multirow[t]{6}{*}{ Race } & White & 8.5 & Ref & & \\
\hline & Asian & 11.7 & 3.248 & 0.451 & $<0.001$ \\
\hline & Native American & 11.5 & 3.022 & 1.240 & 0.015 \\
\hline & Black & 10.0 & 1.522 & 0.577 & 0.008 \\
\hline & Pacific Islander & 5.5 & -2.978 & 2.757 & 0.280 \\
\hline & Mixed & 9.0 & 0.498 & 0.620 & 0.421 \\
\hline \multirow[t]{8}{*}{ Education } & $\begin{array}{l}\text { Bachelor's } \\
\text { Degree }\end{array}$ & 9.1 & Ref & & \\
\hline & $<$ High School & 8.3 & -0.800 & 2.025 & 0.693 \\
\hline & HS Grad/GED & 8.9 & -0.124 & 0.497 & 0.804 \\
\hline & Some College & 8.5 & -0.581 & 0.353 & 0.101 \\
\hline & $\begin{array}{l}\text { Associate's } \\
\text { Degree }\end{array}$ & 9.5 & 0.433 & 0.488 & 0.375 \\
\hline & Master's Degree & 9.2 & 0.135 & 0.473 & 0.775 \\
\hline & $\begin{array}{l}\text { Professional } \\
\text { Degree }\end{array}$ & 8.7 & -0.344 & 1.000 & 0.731 \\
\hline & Doctorate & 9.7 & 0.665 & 1.537 & 0.666 \\
\hline \multirow{4}{*}{$\begin{array}{l}\text { BMI } \\
\text { category }\end{array}$} & Normal Weight & 8.5 & Ref & & \\
\hline & Underweight & 9.6 & 1.137 & 0.825 & 0.168 \\
\hline & Overweight & 9.1 & 0.676 & 0.321 & 0.035 \\
\hline & Obese & 9.7 & 1.222 & 0.372 & 0.001 \\
\hline \multirow{4}{*}{$\begin{array}{l}\text { Geographical } \\
\text { region }\end{array}$} & South & 9.0 & Ref & & \\
\hline & Northeast & 9.1 & 0.102 & 0.401 & 0.800 \\
\hline & Midwest & 8.6 & -0.436 & 0.388 & 0.262 \\
\hline & West & 9.0 & 0.027 & 0.358 & 0.941 \\
\hline
\end{tabular}

*Significant $p$-values are indicated in bold ( $p=<0.05)$; ${ }^{\#}$ total predicted scores within Cues to Action domain as calculated using standard regression equation.

Regression analyses indicate respondent characteristics predict cues to action scores. Certain races (Asian, Native American, and black) could benefit from more recommendations to modify behaviors related to CC risk. Incidence of CC in Native Americans (43.3\%) and non-Hispanic blacks (45.7\%) is higher compared to non-Hispanic whites (38.6\%), suggesting these recommendations are not misplaced (1). Moreover, increased BMI is associated with increased CC risk (44), corresponding to our report of overweight and obese respondents with higher predicted scores in cues to action domain. While CC risk is associated with obesity, dietary interventions of fruits and vegetables may provide protective effects against obesity-related CC through altered gene expression (45).

While this study provides insight into health behaviors and attitudes relative to $\mathrm{CC}$, it is not without limitations. The population of this study was disproportionate to the American population, as most of the participants were from the Southeastern US. Similarly, African Americans were underrepresented. Compared to the national average of about one-third of Americans, more than half of the participants herein earned at least a Bachelor's Degree (46). Furthermore, socioeconomic status and area of educational background was not assessed within the survey instrument, although these factors can influence dietary habits and health-related knowledge (47, 48). Moreover, assessment of nutrition-related literacy could have provided important insight to improving current public health strategies. Additionally, the gut microbiome is known to play an important role in the pathogenesis of CC (49), however, analysis of the microbiome was not within the scope of this study, and therefore limits our understanding of the relationship between diet and CC-related health behaviors. Finally, as with any online survey instrument, there is chance for inaccurate reports of information or disclosures from participants.

These DHCCBS results suggest dietary habits influence the willingness to change health-related behaviors. Participants with the greatest risk of CC are unaware of their risk and are less likely to make the necessary changes to improve their health outcomes. Public health recommendations should provide feasible health behaviors and consider regional differences in dietary patterns. Providing CC screenings for younger adults that also include behavioral risk reduction guidance may decrease CC morbidity and mortality. Dietary recommendations that address dietary habits and behavioral barriers, such as increasing GLV over reduction of RM to obtain benefits may be most beneficial.

\section{DATA AVAILABILITY STATEMENT}

The raw data supporting the conclusions of this article will be made available by the authors, without undue reservation.

\section{ETHICS STATEMENT}

The studies involving human participants were reviewed and approved by Auburn University Institutional Review Board. The patients/participants provided their written informed consent to participate in this study.

\section{AUTHOR CONTRIBUTIONS}

AF, MG, and KS designed the original study. AF obtained funding for the original study. MS, AF, and KS conducted analyses and drafted the original manuscript. All authors provided critical feedback to the final manuscript.

\section{FUNDING}

This research was funded by the Auburn University College of Human Sciences and the Auburn University Research Initiative in Cancer.

\section{SUPPLEMENTARY MATERIAL}

The Supplementary Material for this article can be found online at: https://www.frontiersin.org/articles/10.3389/fnut.2020. 568643/full\#supplementary-material 


\section{REFERENCES}

1. Siegel RL, Miller KD, Jemal A. Cancer statistics, 2020. CA Cancer J Clin. (2020) 70:7-30. doi: 10.3322/caac.21590

2. Zhang X, Wu K, Giovannucci EL, Ma J, Colditz GA, Fuchs CS, et al. Early life body fatness and risk of colorectal cancer in US women and menresults from two large cohort studies. Cancer Epidemiol Biomark Prev. (2015) 24:690-7. doi: 10.1158/1055-9965.EPI-14-0909-T

3. Dong Y, Zhou J, Zhu Y, Luo L, He T, Hu H, et al. Abdominal obesity and colorectal cancer risk: systematic review and meta-analysis of prospective studies. Biosci Rep. (2017) 37:BSR20170945. doi: 10.1042/BSR20170945

4. Zhang FF, Cudhea F, Shan Z, Michaud DS, Imamura F, Eom H, et al. Preventable cancer burden associated with poor diet in the United States. JNCI Cancer Spectrum. (2019) 3:pkz034. doi: 10.1093/jncics/pkz034

5. Alsheridah N, Akhtar S. Diet, obesity and colorectal carcinoma risk: results from a national cancer registry-based middle-eastern study. BMC Cancer. (2018) 18:1227. doi: 10.1186/s12885-018-5132-9

6. Garcia-Larsen V, Morton V, Norat T, Moreira A, Potts JF, Reeves T, et al. Dietary patterns derived from principal component analysis (PCA) and risk of colorectal cancer: a systematic review and meta-analysis. Eur J Clin Nutr. (2019) 73:366-86. doi: 10.1038/s41430-018-0234-7

7. Sesink ALA, Termont DSML, Kleibeuker JH, Van der Meer R. Red meat and colon cancer. Cancer Res. (1999) 59:5704-9. doi: 10.1016/S0016-5085(98)82775-3

8. Sesink ALA, Termont DSML, Kleibeuker JH, Van der Meer R. Red meat and colon cancer: dietary haem, but not fat, has cytotoxic and hyperproliferative effects on rat colonic epithelium. Carcinogenesis. (2000) 21:1909-15. doi: 10.1093/carcin/21.10.1909

9. Gamage SMK, Dissabandara L, Lam AKY, Gopalan V. The role of heme iron molecules derived from red and processed meat in the pathogenesis of colorectal carcinoma. Crit Rev Oncol Hematol. (2018) 126:121-8. doi: 10.1016/j.critrevonc.2018.03.025

10. Ijssennagger N, Belzer C, Hooiveld GJ, Dekker J, van Mil SWC, Müller M, et al. Gut microbiota facilitates dietary heme-induced epithelial hyperproliferation by opening the mucus barrier in colon. Proc Natl Acad Sci USA. (2015) 112:10038. doi: 10.1073/pnas.1507645112

11. Sinha R, Kulldorff M, Chow WH, Denobile J, Rothman N. Dietary intake of heterocyclic amines, meat-derived mutagenic activity, and risk of colorectal adenomas. Cancer Epidemiol Biomarkers Prev. (2001) 10:559-62.

12. Durko L, Malecka-Panas E. Lifestyle modifications and colorectal cancer. Curr Colorectal Cancer Rep. (2014) 10:45-54. doi: 10.1007/s11888-0130203-4

13. de Vogel J, Jonker-Termont DSML, van Lieshout EMM, Katan MB, van der Meer R. Green vegetables, red meat and colon cancer: chlorophyll prevents the cytotoxic and hyperproliferative effects of haem in rat colon. Carcinogenesis. (2005) 26:387-93. doi: 10.1093/carcin/bgh331

14. Corpet DE. Red meat and colon cancer: Should we become vegetarians, or can we make meat safer? Meat Sci. (2011) 89:310-6. doi: 10.1016/j.meatsci.2011.04.009

15. Angelino D, Godos J, Ghelfi F, Tieri M, Titta L, Lafranconi A, et al. Fruit and vegetable consumption and health outcomes: an umbrella review of observational studies. Int J Food Sci Nutr. (2019) 70:652-67. doi: 10.1080/09637486.2019.1571021

16. Hoensch HP, Kirch W. Potential role of flavonoids in the prevention of intestinal neoplasia. Int $J$ Gastrointest Cancer. (2005) 35:187. doi: 10.1385/IJGC:35:3:187

17. Johnson IT. New approaches to the role of diet in the prevention of cancers of the alimentary tract. Mutat Res. (2004) 551:9-28. doi: 10.1016/j.mrfmmm.2004.02.017

18. Makarem N, Lin Y, Bandera EV, Jacques PF, Parekh N. Concordance with world cancer research fund/American institute for cancer research (WCRF/AICR) guidelines for cancer prevention and obesity-related cancer risk in the Framingham Offspring cohort (1991-2008). Cancer Causes Control. (2015) 26:277-86. doi: 10.1007/s10552-014-0509-9

19. Balder HF, Vogel J, Jansen MC, Weijenberg MP, van den Brandt PA, Westenbrink S, et al. Heme and chlorophyll intake and risk of colorectal cancer in the Netherlands cohort study. Cancer Epidemiol Biomarkers Prev. (2006) 15:717-25. doi: 10.1158/1055-9965.EPI-05-0772
20. Archer E, Lavie CJ, Hill JO. The failure to measure dietary intake engendered a fictional discourse on diet-disease relations. Front Nutr. (2018) 5:105. doi: 10.3389/fnut.2018.00105

21. Davis JS, Banfield E, Lee HY, Peng HL, Chang S, Wood AC. Lifestyle behavior patterns and mortality among adults in the NHANES 19881994 population: a latent profile analysis. Prev Med. (2019) 120:131-9. doi: 10.1016/j.ypmed.2019.01.012

22. Wolf AMD, Fontham ETH, Church TR, Flowers CR, Guerra CE, LaMonte SJ, et al. Colorectal cancer screening for average-risk adults: 2018 guideline update from the American Cancer Society. CA Cancer J Clin. (2018) 68:25081. doi: $10.3322 /$ caac. 21457

23. Shapiro JA, Seeff LC, Thompson TD, Nadel MR, Klabunde CN, Vernon SW. Colorectal cancer test use from the 2005 national health interview survey. Cancer Epidemiol Biomarkers Prev. (2008) 17:1623-30. doi: 10.1158/1055-9965.EPI-07-2838

24. Orji R, Vassileva J, Mandryk R. Towards an effective health interventions design: an extension of the health belief model. Online J Public Health Inform. (2012) 4:ojphi.v4i3.4321. doi: 10.5210/ojphi.v4i3.4321

25. Graça J, Oliveira A, Calheiros MM. Meat, beyond the plate. Data-driven hypotheses for understanding consumer willingness to adopt a more plantbased diet. Appetite. (2015) 90:80-90. doi: 10.1016/j.appet.2015.02.037

26. Dehghani-Tafti A, Mazloomy Mahmoodabad SS, Morowatisharifabad MA, Afkhami Ardakani M, Rezaeipandari H, Lotfi MH. Determinants of self-care in diabetic patients based on health belief model. Glob J Health Sci. (2015) 7:33-42. doi: 10.5539/gjhs.v7n5p33

27. Shirazi Zadeh Mehraban S, Namdar A, Naghizadeh MM. Assessment of preventive behavior for cervical cancer with the health belief model. Asian Pac J Cancer Prev. (2018) 19:2155-63. doi: 10.22034/APJCP.2018. 19.8.2155

28. Tola HH, Shojaeizadeh D, Tol A, Garmaroudi G, Yekaninejad MS, Kebede A, et al. Psychological and educational intervention to improve tuberculosis treatment adherence in ethiopia based on health belief model: a cluster randomized control trial. PLoS ONE. (2016) 11:e0155147. doi: 10.1371/journal.pone,.0155147

29. Smith KS, Raney SV, Greene MW, Frugé AD. Development and validation of the dietary habits and colon cancer beliefs survey (DHCCBS): an instrument assessing health beliefs related to red meat and green leafy vegetable consumption. J Oncol. (2019) 2019:2326808. doi: 10.1155/2019/ 2326808

30. Subar AF, Thompson FE, Kipnis V, Midthune D, Hurwitz P, McNutt S, et al. Comparative validation of the block, willett, and national cancer institute food frequency questionnaires: the eating at America's table study. Am J Epidemiol. (2001) 154:1089-99. doi: 10.1093/aje/154.12.1089

31. Rashmi S, Amanda C, Jane C, Thea Z, Susanne M, Adam R, et al. Development of a food frequency questionnaire module and databases for compounds in cooked and processed meats. Mol Nutr Food Res. (2005) 49:648-55. doi: 10.1002/mnfr.200500018

32. Osborne JW, Costello AB. Sample size and subject to item ratio in principal components analysis. Pract Assess Res Eval. (2004) 9:1-9. doi: $10.7275 / \mathrm{ktzq}$-jq66

33. U.S. Census Bureau. Census Regions and Divisions of the United States: U.S. Department of Commerce Economics and Statistics Administration (2016).

34. Zeng L, Ruan M, Liu J, Wilde P, Naumova EN, Mozaffarian D, et al. Trends in processed meat, unprocessed red meat, poultry, and fish consumption in the United States, 1999-2016. J Acad Nutr Diet. (2019) 119:1085-98.e12. doi: 10.1016/j.jand.2019.04.004

35. U.S. Department of Agriculture. Nutrient Intakes From Food and Beverages: Mean Amounts Consumed per Individual, by Gender and Age. What We Eat in America. NHANES. 2015-2016 Beltsville, MD: U.S. Department of Agriculture (2018).

36. Stein CJ, Colditz GA. Modifiable risk factors for cancer. Br J Cancer. (2004) 90:299-303. doi: 10.1038/sj.bjc.6601509

37. Lagerlund M, Hvidberg L, Hajdarevic S, Fischer Pedersen A, Runesdotter S, Vedsted P, et al. Awareness of risk factors for cancer: a comparative study of Sweden and Denmark. BMC Public Health. (2015) 15:1156. doi: 10.1186/s12889-015-2512-9

38. Valli C, Rabassa M, Johnston BC, Kuijpers R, Prokop-Dorner A, Zajac J, et al. Health-related values and preferences regarding meat consumption: 
a mixed-methods systematic review. Ann Intern Med. (2019) 171:742-55. doi: 10.7326/M19-1326

39. Harnack L, Block G, Subar A, Lane S. Cancer prevention-related nutrition knowledge, beliefs, and attitudes of U.S. adults: 1992 NHIS cancer epidemiology supplement. J Nutr Educ. (1998) 30:131-8. doi: 10.1016/S0022-3182(98)70303-6

40. Sullivan HW, Burke Beckjord E, Finney Rutten LJ, Hesse BW. Nutritionrelated cancer prevention cognitions and behavioral intentions: testing the risk perception attitude framework. Health Educ Behav. (2006) 35:866-79. doi: 10.1177/1090198108326164

41. Senore C, Giordano L, Bellisario C, Di Stefano F, Segnan N. Population based cancer screening programmes as a teachable moment for primary prevention interventions. A review of the literature. Front Oncol. (2012) 2:45. doi: 10.3389/fonc.2012.00045

42. Edwards BK, Ward E, Kohler BA, Eheman C, Zauber AG, Anderson RN, et al. Annual report to the nation on the status of cancer, 1975-2006, featuring colorectal cancer trends and impact of interventions (risk factors, screening, and treatment) to reduce future rates. Cancer. (2010) 116:544-73. doi: $10.1002 / \mathrm{cncr} .24760$

43. Bailey CE, Hu CY, You YN, Bednarski BK, Rodriguez-Bigas MA, Skibber $\mathrm{JM}$, et al. Increasing disparities in the age-related incidences of colon and rectal cancers in the United States, 1975-2010. JAMA Surg. (2015) 150:17-22. doi: 10.1001/jamasurg.2014.1756

44. Ma Y, Yang Y, Wang F, Zhang P, Shi C, Zou Y, et al. Obesity and risk of colorectal cancer: a systematic review of prospective studies. PLoS ONE. (2013) 8:e53916. doi: 10.1371/journal.pone.00 53916
45. Roslan NH, Makpol S, Mohd Yusof YA. A review on dietary intervention in obesity associated colon cancer. Asian Pac J Cancer Prev. (2019) 20:1309-19. doi: 10.31557/APJCP.2019.20.5.1309

46. Montez JK, Zajacova A, Hayward MD. Disparities in disability by educational attainment across US states. Am J Public Health. (2017) 107:1101-8. doi: 10.2105/AJPH.2017.303768

47. Vlismas K, Stavrinos V, Panagiotakos DB. Socio-economic status, dietary habits and health-related outcomes in various parts of the world: a review. Central Eur J Public Health. (2009) 17:55-63. doi: 10.21101/cejph.a3475

48. Weiss BD, Hart G, McGee DL, D'Estelle S. Health status of illiterate adults: relation between literacy and health status among persons with low literacy skills. J Am Board Fam Pract. (1992) 5:257-64.

49. Abu-Ghazaleh N, Chua WJ, Gopalan V. Intestinal microbiota and its association with colon cancer and red/processed meat consumption. J Gastroenterol Hepatol. (2020). doi: 10.1111/jgh.15042. [Epub ahead of print].

Conflict of Interest: The authors declare that the research was conducted in the absence of any commercial or financial relationships that could be construed as a potential conflict of interest.

Copyright (C) 2020 Schaberg, Smith, Greene and Frugé. This is an open-access article distributed under the terms of the Creative Commons Attribution License (CC BY). The use, distribution or reproduction in other forums is permitted, provided the original author(s) and the copyright owner(s) are credited and that the original publication in this journal is cited, in accordance with accepted academic practice. No use, distribution or reproduction is permitted which does not comply with these terms. 